\title{
Characterization of Dental Surgeons of Pernambuco State in the COVID-19 Pandemic Context: Preliminary Data
}

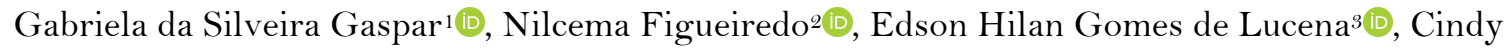 \\ Avani Silva Ceissler ${ }^{4}$, Ronald Pereira Cavalcanti1 10 , Paulo Sávio Angeiras de Goes ${ }^{5}(0)$
}

\begin{abstract}
${ }^{1}$ Public Health Center, Academic Center of Vitória, Federal University of Pernambuco, Vitória de Santo Antão, PE, Brazil. ${ }^{2}$ Academic Area of Social Medicine, Center of Medical Sciences, Federal University of Pernambuco, Recife, PE, Brazil. ${ }^{3}$ Department of Clinical and Social Dentistry, Federal University of Paraíba, João Pessoa, PB, Brazil. ${ }^{4}$ Federal University of Pernambuco, Oral Health Observatory, Recife, PE, Brazil.

${ }_{5}^{5}$ Postgraduate Program in Child and Adolescent Health, Federal University of Pernambuco, Recife, PE, Brazil.
\end{abstract}

Author to whom correspondence should be addressed: Gabriela da Silveira Gaspar, Centro Acadêmico de Vitória, Universidade Federal de Pernambuco, R. Alto do Reservatório, S/N, Bela Vista, Vitória de Santo Antão, PE. Brazil. 55608680. Phone: +55 81991473749. E-mail: gabrielasgaspar@gmail.com.

Academic Editor: Yuri Wanderley Cavalcanti

Received: 22 June 2020 / Accepted: 02 July 2020 / Published: 31 July 2020

How to cite this article: Gaspar GS, Figueiredo N, Lucena EHG, Ceissler CAS, Cavalcanti RP, Goes PSA. Characterization of dental surgeons of Pernambuco state in the COVID-19 pandemic context: preliminary data. Pesqui Bras Odontopediatria Clín Integr. 2020; 20(supp1):e0 145. https://doi.org/10.1590/pboci.2020.152

\begin{abstract}
Objective: To present the results of preliminary research on the characterization of dental surgeons in the state of Pernambuco, during a pandemic of COVID-19. Material and Methods: This is a cross-sectional, descriptive, and exploratory study, whose population was composed of dental surgeons with active enrollment in the Regional Dentistry Council of Pernambuco. Data collection was performed using an electronic form and included characterization of professionals (gender, age, time since graduation, marital status, family income and field of work) and health status (vaccination schedule, presence of comorbidities, biosafety knowledge and testing for COVID-19). Preliminary data correspond to the first week of collection, which were analyzed from the frequency, proportions, and measures of central tendency distributions. Results: Of the 363 dental surgeons, for the field of work, $38.6 \%$ work in both the public and private sectors. Comorbidities related to the worsening of COVID-19 were identified in $35.0 \%$ of participants, $24.5 \%$ are not up to date with influenza and hepatitis vaccines, and $79.3 \%$ have not been tested for COVID19. Regarding the biosafety instructions for COVID-19, 30.7\% received no training. Conclusion: It is necessary to immunize dental surgeons to prevent immunological diseases and expansion of the testing capacity for COVID-19, especially for professionals belonging to the risk group. In addition to guaranteeing the offer of qualification courses on biosafety, which is essential for the safe resumption of activities.
\end{abstract}

Keywords: Oral Health; Dentistry; Dentists; Coronavirus Infections; COVID-19. 


\section{Introduction}

The first cases of SARS-CoV-2 infection (Severe Acute Respiratory Syndrome Coronavirus 2), the causative agent of COVID-19 (Coronavirus Disease), appeared in the city of Wuhan, Hubei province, China [1]. The disease spread rapidly through Chinese territory and, subsequently, cases were identified in other countries such as Japan, Thailand, and the Republic of Korea. With the significant global expansion of cases, the World Health Organization (WHO) declared the disease as a pandemic in March 2020 [2].

The first case of COVID-19 in Brazil was registered on February 26, 2020. And, a month later, community transmission was acknowledged throughout the territory. In the context of a public health emergency of national importance, the Secretariat of Health Surveillance of the Ministry of Health (SVS) adapted the Surveillance System for Acute Respiratory Syndromes, aiming to guide the National Health Surveillance System for simultaneous circulation of coronavirus, influenza and other respiratory viruses [3].

According to the Epidemiological Bulletin number 18, of the Ministry of Health, of June 15, 2020, in Brazil, there were 888 thousand cases confirmed by COVID-19 and 43,959 deaths [3]. However, these data do not reflect the real prevalence of COVID-19 in the population, since, in the country, the tests are almost exclusively performed on people with symptoms, especially in the most severe cases, that is, it fails to diagnose the great majority of those contaminated, who present mild symptoms, or even, are asymptomatic [4].

According to the Epidemiological Bulletin of the State Health Secretariat, 06/16/2020, the state of Pernambuco registered 46,427 confirmed cases, of which 17,405 were serious and 29,022 were mild, placing it in second place in the Northeast Region, with the highest number of deaths of the disease. So far, confirmed severe cases of the disease are distributed in 168 (90.8\%) municipalities in Pernambuco, in addition to the Fernando de Noronha Archipelago [5].

Once the virus is present within oral tissue cells, this causes the aerosol generated during dental procedures to be potentially contaminated. Thus, dental practice, although indispensable for maintaining general health, has been considered to be at high risk of contagion [6]. The fear of contamination has led some people to avoid attending the dental service, considered after the reopening of health services, which tends to increase the number of emergencies or more complex procedures. Another effect to be analyzed will consider possible needs for adaptations in the dental office to reduce or eliminate the viruses present in aerosols and on the surfaces of the service environment, and also, dentists need to adapt to this new routine, preserving their health and that of the patient.

Due to the profound impacts of the pandemic on the provision of dental services, investigating mechanisms to adapt this practice may contribute to guarantee the provision of this essential service to society. As it is a topic of national and international interest, the results obtained with this study intend to generate evidence about the risk that dental activity presents during the pandemic period for professionals in the area. Thus, the objective is to present the results of preliminary research on the characterization of dental surgeons in the state of Pernambuco, during a pandemic of COVID-19.

\section{Material and Methods}

\section{Study Design}

The present study has a quantitative, cross-sectional, descriptive, and exploratory approach. For the communication, respondents were considered in the first eight days of the survey, from June $9^{\text {th }}$ to $16^{\text {th }}, 2020$.

Population 
A census was conducted with all 9,793 dental surgeons in the state of Pernambuco, Brazil, with active enrollment in the Regional Dentistry Council of Pernambuco (CRO-PE). All dental surgeons with active enrollment in the CRO-PE were included. Those who did not have an e-mail, who showed any inconsistency in the e-mail or telephone number, who did not have the Whatsapp messaging app, which did not make access to the form possible and professionals with unsigned or suspended registrations were excluded.

\section{Data Collection}

The instrument for data collection was developed and applied in an electronic form, using Google ${ }^{\circledR}$ Forms. These were sent through the official e-mail list of the CRO-PE, through the message transmission list of the Whatsapp messaging app, via text messaging type messages and posted on the social media networks of that entity. This protocol was established to minimize losses and enhance results to have a high response rate and due to the need for social distancing, which would make it impossible to collect data face-to-face.

The characterization of the investigated professionals considered the socioeconomic profile: gender, age, time since graduation, marital status, family income and field of work (public and/or private). To analyze the health situation, the variables: updated vaccination schedule, knowledge about biosafety for COVID-19, testing for COVID-19 and presence of comorbidities were analyzed.

\section{Data Analysis}

The data were exported to the Excel software, version 2000 (Microsoft Corp, United States), and subsequently analyzed from the distribution of frequencies, percentages, mean and median. To guarantee the respondent's identity, the professional's registration number provided by the CRO-PE and the one registered by the respondent in the questionnaire were crossed. However, to guarantee the participant's confidentiality, all participants were identified by a number, thus guaranteeing confidentiality, and making it impossible for the professional to be recognized.

\section{Ethical Aspects}

The research followed all the precepts of the Resolution 466/12 of the Brazilian National Health Council, related to research in human beings, and was approved by the Research Ethics Committee of the Academic Center of Vitória (CEP/CAV) of the Federal University of Pernambuco, under CAAE $n^{\circ}$. 32362 120.3.0000.9430, and Report $n^{\circ}$. 4.068.546.

\section{Results}

One week after the start, the survey received responses from 363 dental surgeons. $72.5 \%$ of these are female, $58.1 \%$ are married or in a common-law marriage and $33.9 \%$ are single. As for family income, $66.1 \%$ is equal to or greater than five Brazilian minimum wages, $23.1 \%$ is 3 to 4 minimum wages and $10.7 \%$ corresponds to a maximum of 2 minimum wages. On average, the participants have 14.6 years of graduation. Regarding postgraduate education, $55.9 \%$ have specialization or residency as the highest degree and $22 \%$ do not have postgraduate degrees. 38.6\% work professionally in both public and private sectors.

Analyzing the health situation of these professionals, it was identified that $35.0 \%$ has some type of comorbidities related to the worsening of the symptoms of COVID-19. Among the main ones, arterial hypertension (14.3\%), pulmonary disease, respiratory failure or asthma (9.6\%), obesity (8.8\%), and diabetes 
(4.1\%) stand out. Regarding the vaccination schedule, $24.5 \%$ are not up to date with one of influenza or hepatitis vaccines, $79.3 \%$ of the dentists were not tested for COVID-19, among those who performed testing, $70.6 \%$ had negative results. As for training for clinical care, $30.3 \%$ of the respondents said they had not received any instruction through training or a course on biosafety for COVID-19.

Table 1. Characterization of dental surgeons according to socioeconomic profile and health situation.

\begin{tabular}{|c|c|c|}
\hline Variables & $\mathbf{N}$ & $\%$ \\
\hline \multicolumn{3}{|l|}{ Socioeconomic Profile } \\
\hline \multicolumn{3}{|l|}{ Gender } \\
\hline Female & 263 & 72.5 \\
\hline Male & 100 & 27.5 \\
\hline \multicolumn{3}{|l|}{ Marital Status } \\
\hline Married/Common-law marriage & 211 & 50.1 \\
\hline Divorced & 25 & 6.9 \\
\hline Single & 124 & 34.1 \\
\hline Widow & 3 & 0.8 \\
\hline \multicolumn{3}{|l|}{ Family Income* } \\
\hline Less than 1 minimum wage & 3 & 0.8 \\
\hline 1 to 2 minimum wages & 36 & 9.9 \\
\hline 3 to 4 minimum wages & 84 & 23.1 \\
\hline Equal to or greater than 5 minimum wages & 240 & 66.1 \\
\hline Mean of graduation time (in years) & 14.6 & \\
\hline \multicolumn{3}{|l|}{ Highest degree, in case of postgraduate education } \\
\hline Doctorate & 39 & 10.7 \\
\hline Masters & 41 & 11.3 \\
\hline Specialization/Residency & 203 & 55.9 \\
\hline No postgraduate degree & 80 & 22.0 \\
\hline \multicolumn{3}{|l|}{ Field of work you carry out professional activities } \\
\hline Only in the private sector & 123 & 33.9 \\
\hline Only in the public sector & 92 & 25.3 \\
\hline In both (private and public sectors) & 140 & 38.6 \\
\hline Does not practice clinical dentistry & 8 & 2.2 \\
\hline \multicolumn{3}{|l|}{ Health Situation } \\
\hline \multicolumn{3}{|l|}{ Presence of Comorbidity } \\
\hline Yes & 127 & 35.0 \\
\hline No, none & 236 & 65.0 \\
\hline \multicolumn{3}{|l|}{ Testing } \\
\hline Was tested for COVID-19 and the result was negative & 53 & 14.6 \\
\hline Was tested for COVID-19 and the result was positive & 22 & 6.1 \\
\hline Was not tested for COVID-19 & 288 & 79.3 \\
\hline \multicolumn{3}{|l|}{ Updated Vaccination Schedule } \\
\hline No, for both & 18 & 5.0 \\
\hline Yes, for both (hepatitis and influenza) & 274 & 75.5 \\
\hline Yes, only for influenza (2020 vaccine) & 25 & 6.9 \\
\hline Yes, only for hepatitis B & 46 & 12.7 \\
\hline \multicolumn{3}{|l|}{ Received instructions on biosafety for COVID-19 } \\
\hline No, none & 110 & 30.3 \\
\hline Yes & 253 & 69.7 \\
\hline
\end{tabular}

\section{Discussion}


The present work is the first report that seeks to characterize dentists on different aspects, including the socioeconomic profile, health situation and knowledge about biosafety for COVID-19. Their findings will help to reflect on the necessary changes to be adopted by this professional group in the post-pandemic period.

The research findings point to a predominance of women in accordance with the literature on the participation of this gender in Dentistry [7]. Therefore, it is important to reflect on gender issues within the discussions of the impact of COVID-19 and its economic and social effects for Dentistry, considering the greater risk of women becoming infected because they are the majority, but also the consequences of informal occupational bonds, greater economic vulnerability, greater burden of responsibility for family care within the domestic environment and little occupation in the representation spaces and leadership [8].

The National Oral Health Policy - Smiling Brazil (“Brasil Sorridente”) opened jobs in the public service [9] and thus brought dentist's aspiration for occupation in the public sector, aiming at financial stability, easing the uncertainty of practicing in the private sector. Data from 2014 indicate that one-third of the country's dental surgeons work in the Unified Health System - SUS [10], however, they also seek to work in the private sector [11], corroborating the results of this study, in which most respondents reported working in both sectors. Thus, discussions about the transformations in the routine of dental work imposed by the pandemic must consider this double relation in the economic fields, since it is the same professional practicing in different workplaces.

Health professionals are immersed in a background where occupational risk is part of their daily lives. Consequently, these risks and the fear of becoming ill and/or its realization directly interfere in the performance of workers with repercussions on their quality of life [12]. A study carried out with dental surgeons in India shows that only $10 \%$ are confident with the return of post-pandemic care. Among the factors considered for those who reported being hesitant are their health and financial issues [13].

Personal health is an important issue to consider in the face of the risk of contamination. The findings of this research identified an important number of professionals with chronic diseases that are risk factors for COVID-19. This health condition can keep them away from work for fear of getting worse in case of contamination. The literature reports the association between the presence of comorbidities and the worsening of the outcomes of patients with the infection of the new coronavirus, in addition to pointing out that the increase in the number of these comorbidities increases the severity of the outcomes [14].

It was observed that almost one-third of the professionals did not receive any instructions through training or a course on biosafety for COVID-19, which can result in contamination. An alternative to fill this gap may be virtual courses, being a possible educational tool in periods of social isolation [15].

The vaccination schedule needs to be updated to minimize occupational risk since immunization promotes protection for professionals and users. In addition to being safe and efficient, it is available in the Unified Health System (SUS). There is evidence that points to the effectiveness of the influenza vaccine in reducing the incidence of cases and absence from work among health workers [16]. For hepatitis B, similar findings were identified in dental surgeons in the public health system in São Paulo [17].

The small amount of testing that is being carried out in all regions of Brazil is reflected in the preliminary results of this study, where less than a quarter of the professionals took the test for COVID-19. The expansion of the testing capacity of the population and health professionals is an imperative measure to generate the information and indicators necessary to support the best strategies to develop projections that can reflect the social and demographic diversity of the society, allowing a safe return to normal and minimizing the possibility of subsequent epidemic outbreaks [18]. 
This study has the limitation of presenting preliminary data; however, it is possible to reflect on the health situation of dental surgeons in Pernambuco in the face of the greatest public health crisis of this century. It is noteworthy that data collection will continue to be carried out and with a larger number of the sample, analytical measures can be evaluated and inferences about the financial and emotional impact, and change in the work process, in addition to enabling the expansion of the analysis to other categories of oral health professionals, such as oral health assistants and technicians.

\section{Conclusion}

The new coronavirus has brought about new demands for dentistry, both immediately and long term, and for its solution, partnerships between professionals, professional entities, government and universities are necessary to propose, implement and monitor actions that subsidize them.

The research of the impact of COVID-19 in the professional practice of dental surgeons presents, the preliminary results, the need for immunization of these professionals for immunological diseases, the expansion of the testing capacity for COVID-19 to improve the accuracy of the actions to control the disease, including special attention to professionals belonging to the risk group. Another verified demand was qualification on biosafety, which is critical for the safe resumption of activities. These results are expected to be socially useful, as they can be used in the planning and reorganization of health services in public and private sectors.

\section{Authors' Contributions}

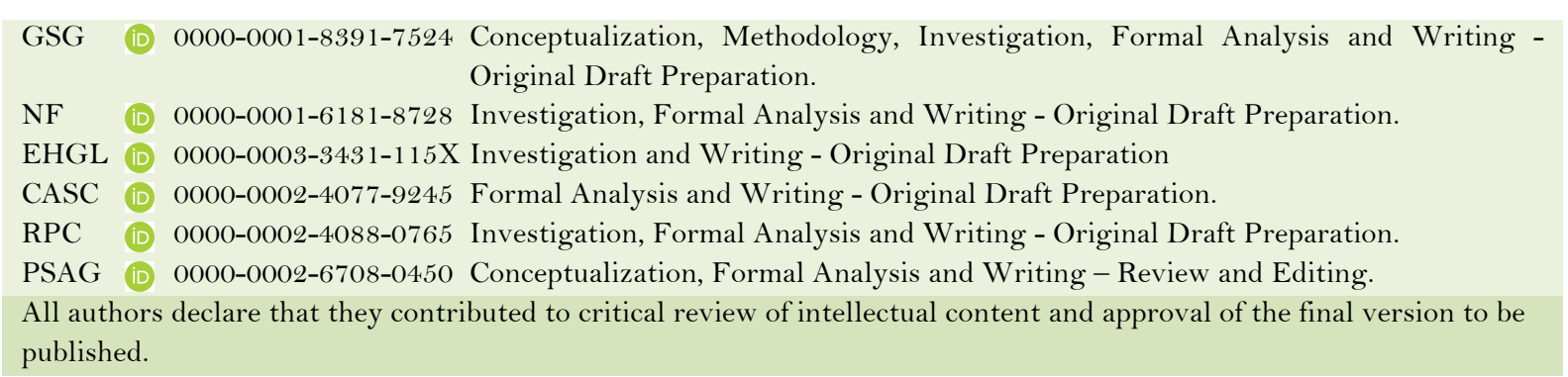

\section{Financial Support}

None.

\section{Conflict of Interest}

The authors declare no conflicts of interest.

\section{Acknowledgements}

We thank the support of the Regional Council of Dentistry and the Pernambuco Health Secretariat through the State Coordination of Oral Health.

\section{References}

[1] Chen, N, Zhou M, Dong X, Qu J, Gong F, Han Y, et al. Epidemiological and clinical characteristics of 99 cases of 2019 novel coronavirus pneumonia in Wuhan, China: a descriptive study. Lancet 2020; 395(10223):507-13. https://doi.org/10.1016/So140-6736(20)30211-7

[2] World Health Organization. Coronavirus disease (COVID-19) pandemic. Novel coronavirus (2019-nCoV) Situation Report - 52. 2020. Available from: https://www.who.int/docs/default-source/coronaviruse/situationreports/20200312-sitrep-52-covid-19.pdf?sfvrsn=e2bfc9c0_4. [Accessed on June 07, 2020]. 
[3] Brasil. Ministério da Saúde. Secretaria de Vigilância à Saúde. Painel de casos de doença pelo coronavírus 2019 (COVID-19) no Brasil. Available from: https://covid.saude.gov.br/. [Accessed on June 07, 2020].

[4] Hallal PC, Horta BL, Barros AJD, Dellagostin OA, Hartwig FP, Silveira MF, et al. Trends in the prevalence of COVID-19 infection in Rio Grande do Sul, Brazil: repeated serological surveys. Ciênc Saúde Coletiva 2020; 25(supl.1): 2395-2401. https://doi.org/10.1590/1413-81232020256.1.09632020

[5] Pernambuco. Secretaria de Saúde de Pernambuco. Secretaria Executiva de Vigilância à Saúde. Centro de Informações Estratégicas de Vigilância em Saúde de Pernambuco. Informe Epidemiológico $n^{\circ}$ 107/2020. Available from: https://www.cievspe.com/novo-coronavirus-2019-ncov. [Accessed on June 07, 2020].

[6] Peng X, Xu X, Li Y, Chend L, Zhou X, Ren B. Transmission routes of 2019-nCoV and controls in dental practice. Int J Oral Sci 2020; 12:9.

[7] Morita MC, Haddad AE, Araújo ME. Perfil Atual e Tendências do Cirurgião-Dentista Brasileiro. Maringá: Dental Press International; 2010. [In Portuguese]

[8] Wenham C, Smith J, Morgan R. COVID-19: the gendered impacts of the outbreak. Lancet 2020; 395(10227):846-8. https://doi.org/10.1016/So140-6736(20)30526-2

[9] Cayetano MH, Carrer FC, Gabriel M, Martins FC, Pucca Jr. GA, Araujo MA. Política Nacional de Saúde Bucal Brasileira (Brasil Sorridente): Um resgate da história, aprendizados e futuro. Univ Odontol 2019; 38(80):1-23 https://doi.org/10.11144/Javeriana.uo38-80.pnsb [In Portuguese]

[10] Cascaes AM, Dotto L, Bomfim RA. Trends in the dental surgeon workforce in Brazil 2007-2014: a time series study using data from the National Registry of Health Services. Epidemiol Serv Saúde 2018; 27(1):e201723615. https://doi.org/10.5123/s1679-49742018000100015

[11] Cardoso AL, Vieira ALS, Machado MH. Labour market for dentists in Brazil. Divulg Saúde Debate 2010; 45(5):71-9. [In Portuguese]

[12] Noronha MSM. Occupational risks and pathologies in dental surgeons from the Center for Dental Specialties. RFO UPF 2013; 18(3):316-20.

[13] Kinariwala N, Perera Samaranayake L, Perera I, Patel Z. Concerns and fears of Indian dentists on professional practice during the Coronavirus Disease-2019 (COVID-19) Pandemic. Oral Dis 2020; 10.1111/odi.13459. https://doi.org/10.1111/odi.13459

[14] Ye C, Zhang S, Zhang X, Cai H, Gu J, Lian J, et al. Impact of comorbidities on patients with COVID-19: a large retrospective study in Zhejiang, China. J Med Virol 2020. https://doi.org/10.1002/jmv.26183

[15] Quijano-Escate R, Rebatta-Acuña A, Garayar-Peceros H, Gutierrez-Flores KE, Bendezu-Quispe G. Aprendizaje en tiempos de aislamiento social: cursos masivos abiertos en línea sobre la COVID-19. Rev Peru Med Exp Salud Publica 2020; 37(2):375-7. https://doi.org/10.17843/rpmesp.2020.372.5478 [In Spanish]

[16] Imai C, Toizumi M, Hall L, Lambert S, Halton K, Merollini K. A systematic review and meta-analysis of the direct epidemiological and economic effects of seasonal influenza vaccination on healthcare workers. PLoS One 2018; 13(6):e0198685. https://doi.org/10.1371/journal.pone.0198685

[17] Garbin CAS, Vanzo KLT, Moimaz SAS, Garbin AJI, Chiba FY. Vaccination coverage and immunity against hepatitis $\mathrm{B}$ in public health dentists. Rev Soc Bras Med Trop 2019; 52:e20180534.

https://doi.org/10.1590/0037-8682-0534-2018

[18] Barreto ML, Barros AJD, Carvalho MS, Codeço CT, Hallal PRC, Medronho RA, et al. What is urgent and necessary to inform policies to deal with the COVID-19 pandemic in Brazil? Rev Bras Epidemiol 2020; $23:$ e200032. https://doi.org/10.1590/1980-549720200032 